\title{
FUNCTIONALLY ACTIVE INTRATHORACIC NEUROBLASTOMA
}

\author{
BY
R. ABBEY SMITH, T. P. WHITEHEAD, LORNA MORRIS and H. PARRY WILLIAMS
From the Thoracic Surgical Unit, King Edward VII Memorial Chest Hospital, Warwick, and Paediatric Department, Coventry and Warwickshire Hospital

(RECEIVED FOR PUBLICATION JUNE 7, 1960)

It is apparent that, under certain circumstances so far undefined, neuroblastomata may be associated with a secretion of pressor amines in sufficient amounts to cause significant symptoms. Mason, Hart-Mercer, Millar, Strang and Wynne (1957) reported an infant with an adrenaline secreting intrathoracic neuroblastoma which was successfully removed. The preoperative symptoms, sweating and pallor, were completely relieved by extirpation of the tumour. We wish to report on a child in whom we were able to reach the correct diagnosis before operation by referring to the description by Mason and his colleagues. The symptomatology, situation and histology of the tumour and the postoperative course were similar to the infant described by Mason et al. (1957). As these authors stated, the importance of these findings appears to lie beyond their immediate interest.

\section{Case Report}

C.H. was the second born child of healthy parents. She weighed $7 \mathrm{lb} .6 \mathrm{oz}$. at birth and was a full-term baby. She was regarded by her parents as quiet and easily manageable, apart from occasional episodes of vomiting, up to the age of 20 months. From about this age it was noted that each time the child was taken up from its cot (after its morning rest, at 10 o'clock at night and on rising in the morning) the pillow and pillow case were drenched. For some time it was thought that in spite of attempts to keep the child dry she was wetting the bed and pillow. The child's head was so wet that her hair was always stuck down on to her head and neck. During the day, especially after meals, she sweated profusely, especially noticeable on the upper lip and around the hair line, for no apparent reason. At the age of 2 she was treated for roundworms and from then until her admission to hospital at the age of 3 years 8 months she was described as a lazy child, content to be all day in her pram and be 'pushed around by the other children'. The sweating continued, more noticeable some days than others, but never causing severe prostration. The hair was always so wet that its texture was altered and its growth limited. Her mother never noted any loss of consciousness or fainting attack, but stated that at times the child seemed to go deaf and very pale in colour. On these occasions she seemed distant and uncooperative.

On admission to hospital the child weighed $26 \mathrm{lb}$. She was stunted, listless and apathetic. Her face was pale and beads of perspiration could be seen on the lips and forehead. Though not acutely ill the child seemed generally out of condition.

Another positive finding on physical examination was a fullness in the region of the posterior ends of the 11 th and 12th ribs on the left side. This was caused by a firm irregular mass, apparently growing from the 11th intercostal space. This mass was neither tender nor fluctuant. A radiograph of the child's chest is shown (Fig. 1) and the relationship of the tumour to the 11th and 12th ribs in Fig. 2. Examination of the blood showed $\mathrm{Hb} 12.3 \mathrm{~g} . / 100 \mathrm{ml}$., the red cells normal, and white cells $8,300 /$ c.mm. (lymphocytes $66 \%$, polymorphs $24 \%$ and eosinophils $2 \%$ ). The blood urea was $25 \mathrm{mg}$./ $100 \mathrm{ml}$., serum sodium $135 \mathrm{mEq} /$ litre, serum potassium $4.6 \mathrm{mEq} / \mathrm{litre}$ and serum chlorides $100 \mathrm{mEq} / \mathrm{litre}$. The faeces contained neither ova nor parasites. No abnormality was seen in a radiograph of the skull. A diagnosis of an adrenaline secreting intrathoracic neuroblastoma was made and the child was kept under observation in order to assess the extent of functional activity of the tumour, its daily variation and to assess factors promoting safe removal of the tumour. During this period of observation the child's temperature rose to $100^{\circ} \mathrm{F}$. intermittently, the resting pulse rate varied between 100 and 140 per minute and the blood pressure between $95 / 50 \mathrm{~mm}$. Hg and $125 / 65 \mathrm{~mm}$. Hg. She did not appear to be more distressed one day than another, gave no indication of any extrinsic factor causing elevation of the blood pressure and generally the clinical impression was reached that adrenaline secretion was at a constant level. For most of the time the child lay in her cot apathetic and uncomplaining, always perspiring and at times quite profusely.

Urinary Assay of Catecholamines. The screening test suggested by Hingerty (1957) for catecholamines in urine was positive on three occasions. Visual comparison showed a urinary catecholamine excretion of $600 \mu \mathrm{g}$./ 24 hours and 1,140 $\mu \mathrm{g}$. $/ 24$ hours (expressed as nor- 


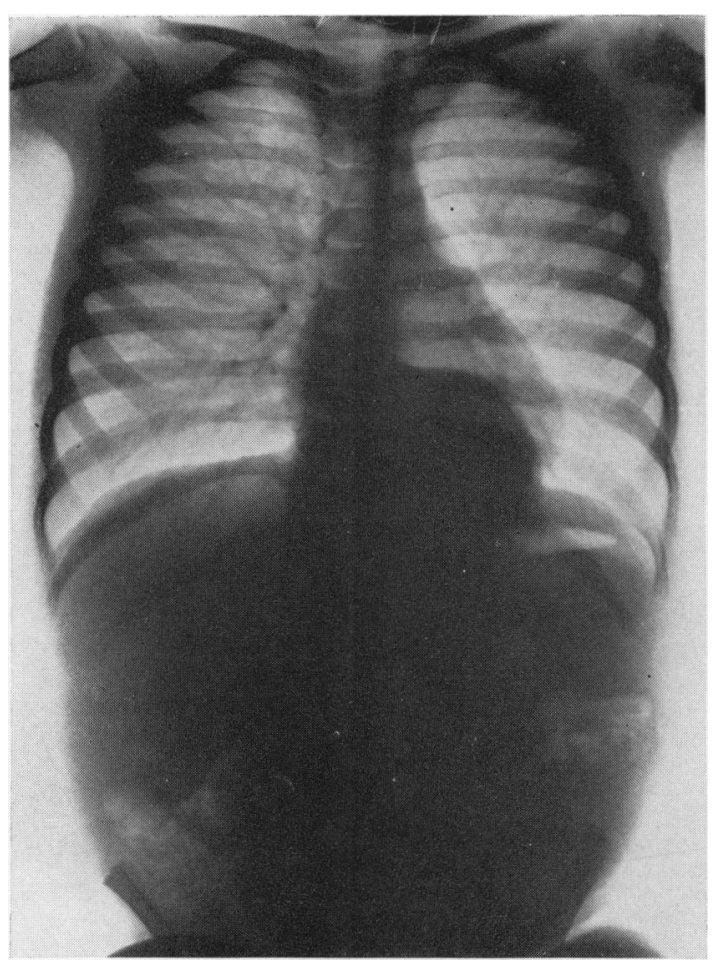

Fig. 1.-Radiograph of the chest immediately before operation. The tumour lies behind the heart shadow.

adrenaline) on two consecutive days. In adults the normal excretion of catecholamines is below $185 \mu \mathrm{g} . / 24$ hours. Mr. B. A. Callingham of the School of Pharmacy assayed the urinary pressor amines in a 24 hours' collection of urine and showed them to be $326 \mu \mathrm{g} . /$ 24 hours $(70 \%$ of the pressor amines were present as noradrenaline).

Operation. The child was 3 years and 10 months at the time of operation. She was premedicated with chlorpromazine $13.0 \mathrm{mg}$., promethazine $13.0 \mathrm{mg}$., pethidine $50 \mathrm{mg}$. and atropine $1 / 100$ grain. Scoline $50 \mathrm{mg}$. intramuscularly was followed by oral intubation and anaesthesia maintained by nitrous oxide, oxygen and tubarine. Barbiturates were not used at any stage.

A curved incision was made over the tumour. The 11 th and 12th left ribs with periosteum and the tissues in the intercostal space were mobilized intact and the pleural cavity opened. An extension of the tumour into the erector spinae muscle was mobilized and the firm lobulated main tumour, lightly adherent to the vertebral body, was dissected out. Its exact relationship to the sympathetic chain could not be identified, nor was it possible to be certain of the amount of residual tumour in the nerve filaments leaving the intervertebral spaces adjacent to the tumour. It did, however, seem certain that there was no intrathecal extension. The

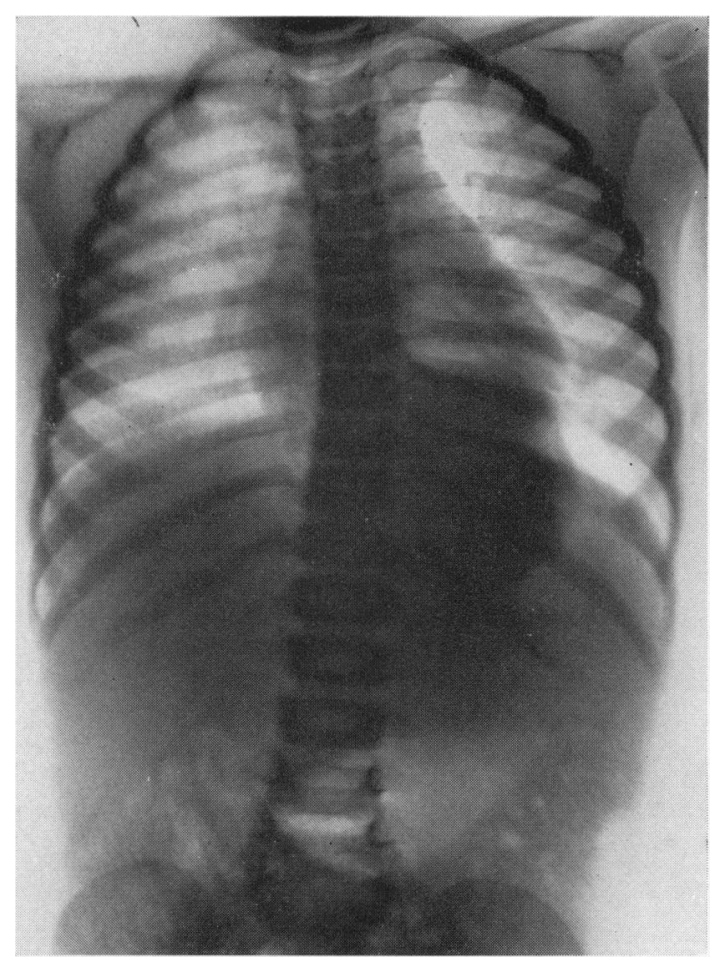

FIG. 2.-High penetration view to show erosion of posterior ends of 11 th and 12 th left ribs.

lower lobe of the lung was normal. The left kidney was not examined. The tumour, most of the 11 th rib and the whole of the 12 th rib were removed. The pleural cavity was closed without drainage by suture of the diaphragm to the 11 th rib remnant. The blood pressure fluctuations during the operation are shown in the accompanying chart (Fig. 3). During the operation $360 \mathrm{ml}$. of whole blood were transfused. Within 24 hours of the operation the blood pressure became constant at $100 / 50 \mathrm{~mm}$. $\mathrm{Hg}$ and the sweating ceased. Before the 10th day after operation the child had started to take more interest. On the 12th day Hingerty's screening test for urinary catecholamines was negative and biological assay confirmed a normal excretion of noradrenaline. The child progressed satisfactorily.

Pathology of Tumour. The tumour was examined in detail by Dr. D. F. Barrowcliff who reports:

'A coarsely lobulated tumour weighing 125 grams and measuring $7 \times 7 \times 4 \mathrm{~cm}$. (Fig. 4). The sulci are deep (up to $1 \mathrm{~cm}$. in places). Two pieces of rib $3.5 \mathrm{~cm}$. long are attached to one pole. Growth does not appear to invade ribs or intercostal muscles. The cut surface shows radial striations, is mostly pale fawn or grey, but is flecked with tiny spots of bright yellow material. The consistency to the cutting knife is moderately firm and in places gritty. 


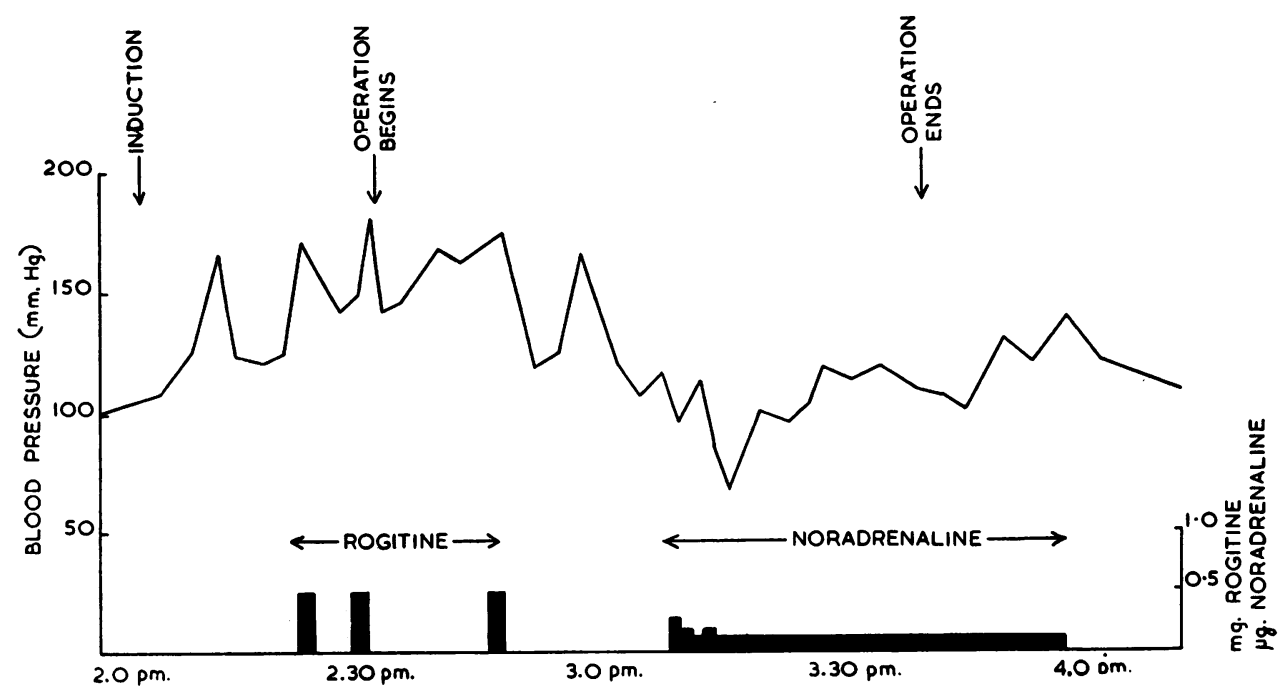

Fig. 3.-Chart of blood pressure fluctuation during operation.

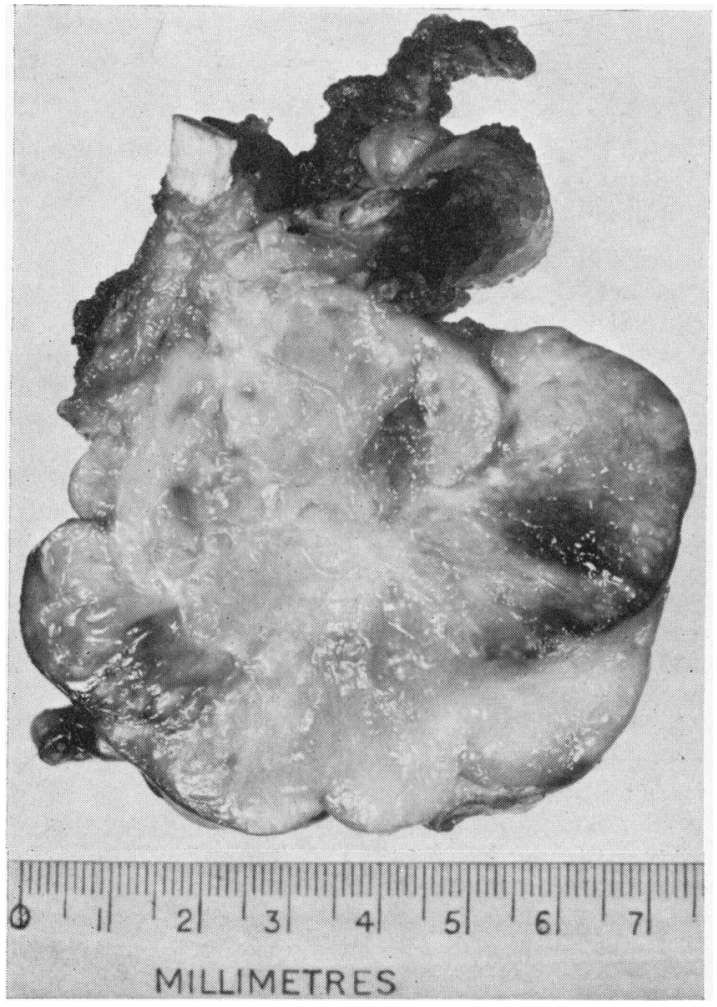

Fig. 4.-Cut surface of tumour. Portions of 11 th and 12 th ribs are attached to the tumour.
'Most of the tissue was fixed in formol-saline, the rest in Orth's fluid.

'Sections from a total of 20 blocks were examined.

'Representative slides were stained with haematoxylip and eosin, van Gieson, von Kossa, silver impregnations periodic acid Schiff and toluidine blue.

'All sections show bundles or whorls of nerve fibrils which in a few places are closely packed, orderly and regular and studded with adult ganglion cells, resembling a ganglio-neuroma (Fig. 5). In most areas the nerve fibres are loosely arranged in irregular bands, and these bands enmesh groups or sheets of cells which vary from small darkly staining sympathogonia to large, nearly mature ganglion cells (Fig. 6).

'The last-named have a large nucleus measuring approximately $30 \mu$ in diameter, with a prominent nucleolus and a radially-arranged chromatin network. Binucleate forms are not uncommon; many of the nuclei are eccentrically or peripherally placed. The cytoplasm is finely granular with a homogeneous ground-glass appearance. A few of the more mature forms show Nissl's granules.

'The cell which is considered to be intermediate between the sympathogonia and the mature ganglion cell is shown in Fig. 7. This is polygonal, has a finely eosinophilic cytoplasm, and a nucleus with a wellformed nuclear membrane. Amongst these lie smaller cells, some of which show a coarsely granular yellowishbrown pigment in their cytoplasm. Such chromepositive cells are uncommon. When present they tend to occur amongst the less differentiated elements, none being found amongst the mature ganglion cells. Neighbouring nerve fibrils are sometimes similarly stained, though more faintly.

These intermediate cells occur in the largest foci, 


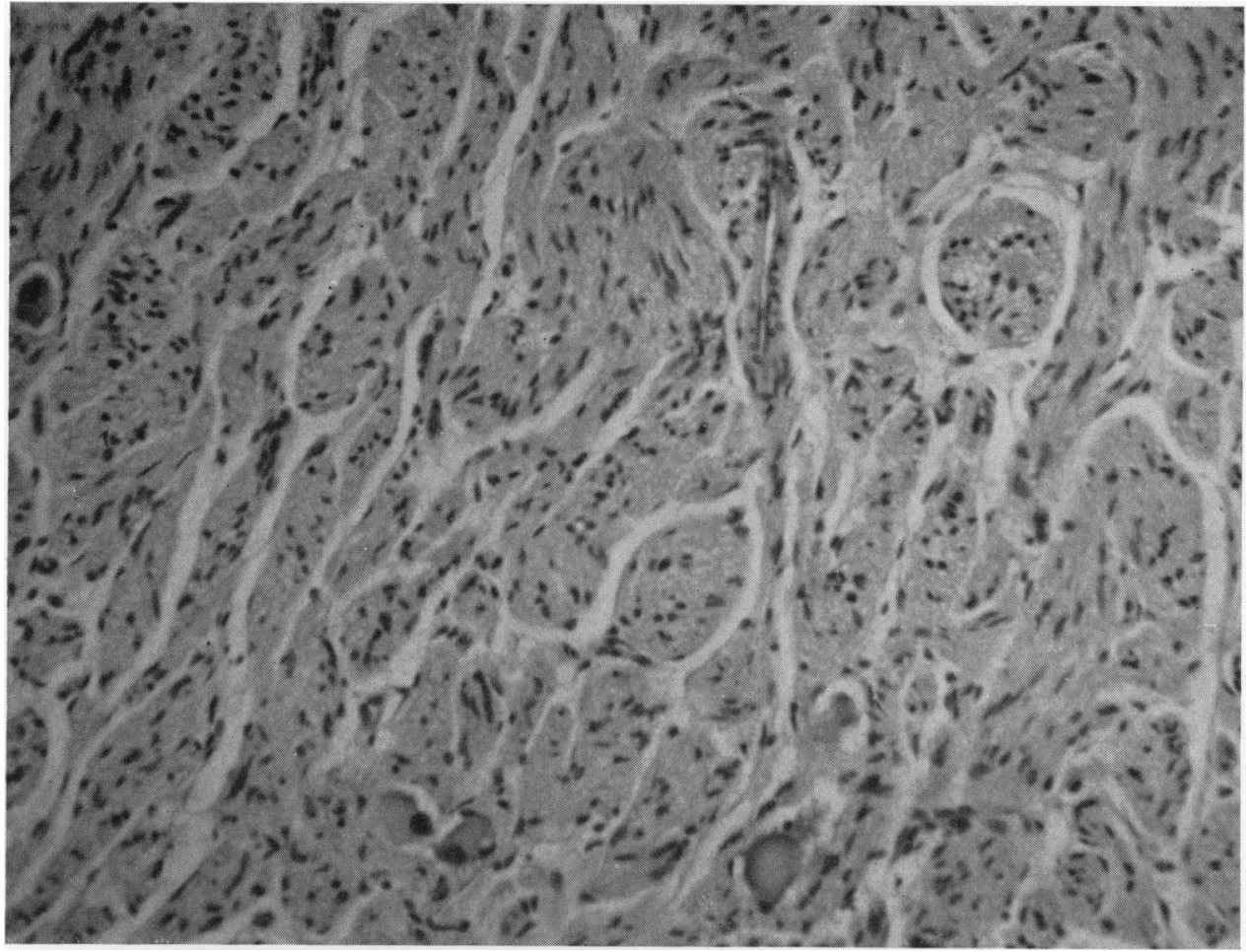

Fig. 5.- $(\times 76$.

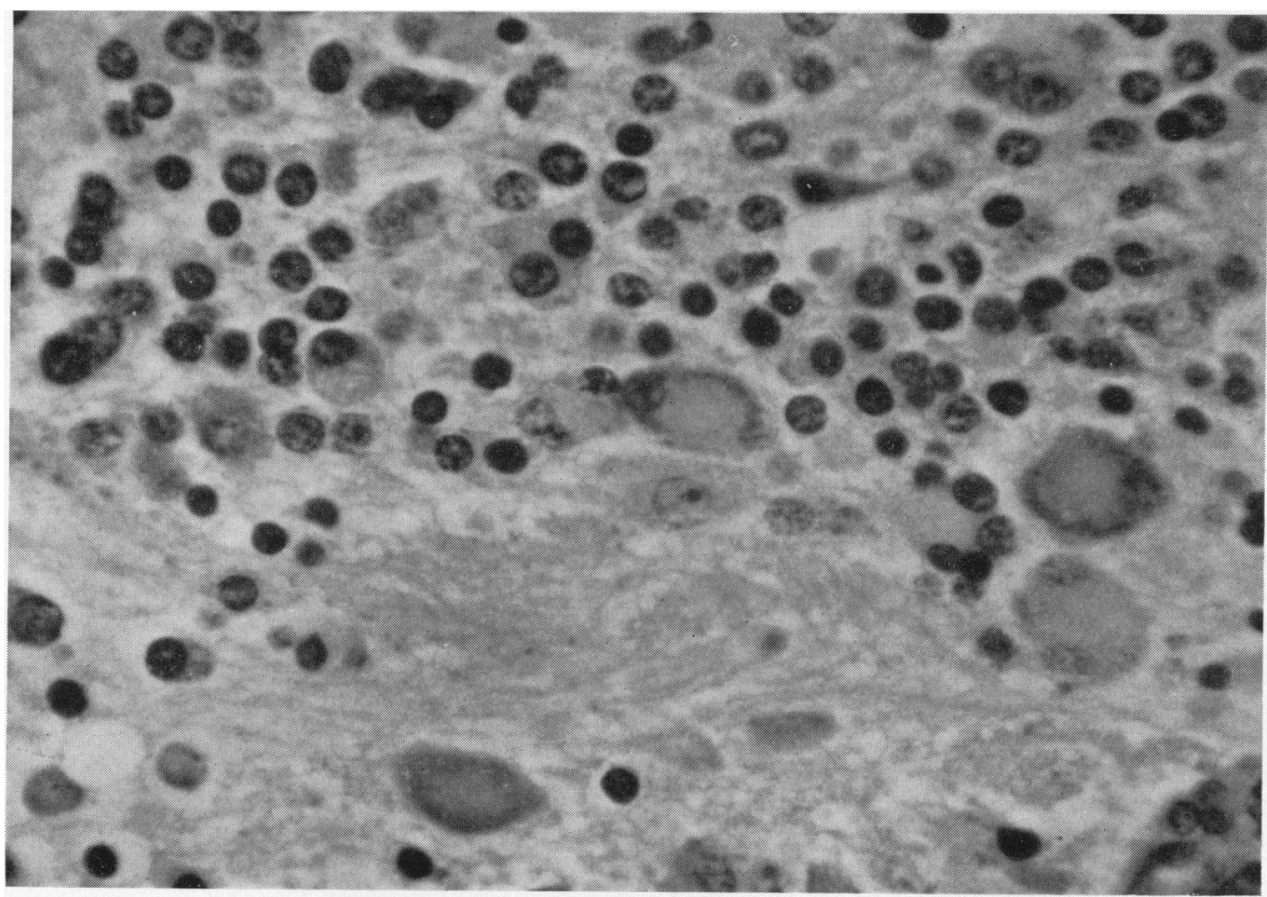

Fig. 6. $-(\times 215$. 


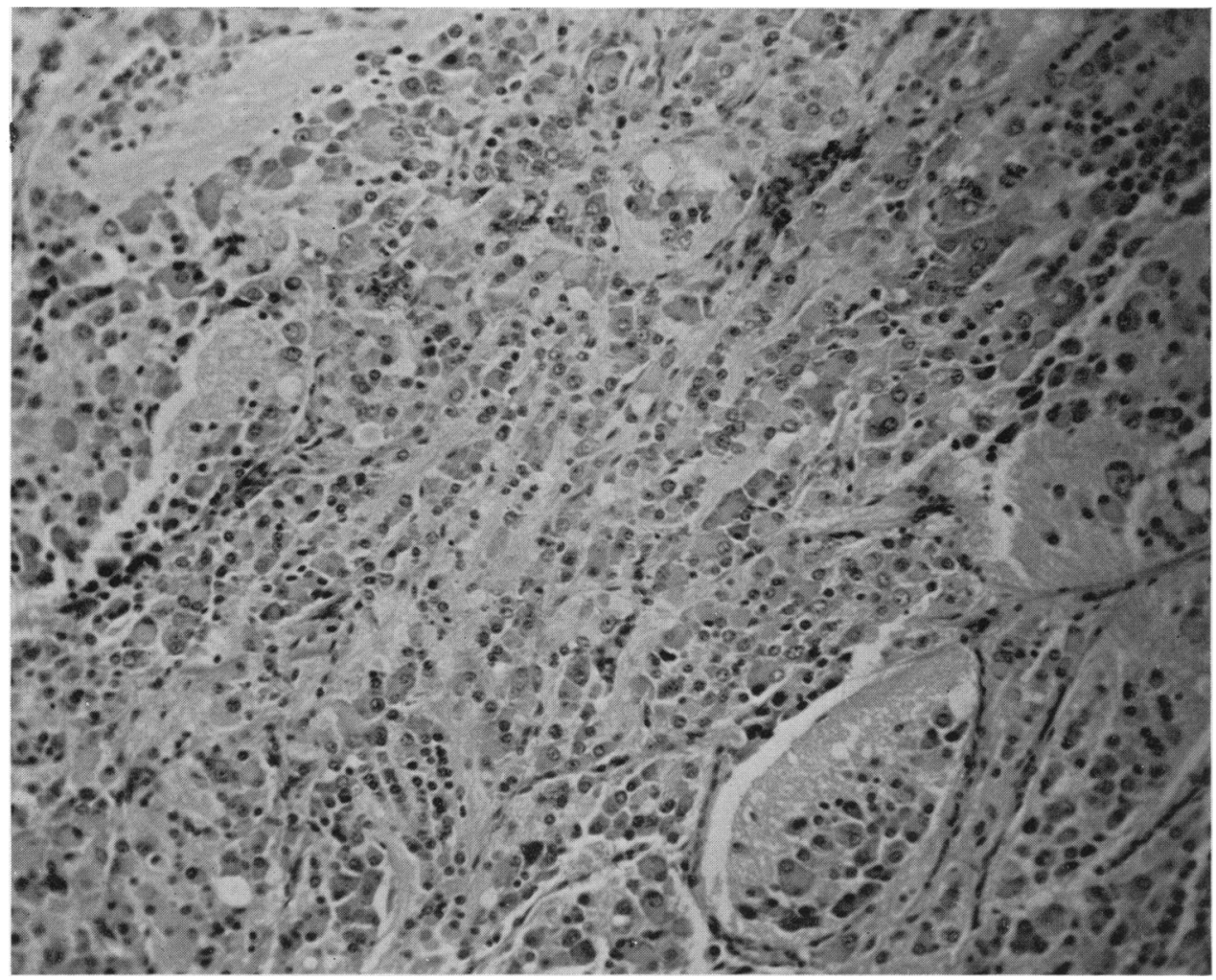

Fig. 7.- $(\times$ 54. $)$

often extending in solid sheets over several microscopic fields. The centres of such sheets may very rarely show necrosis. More common are islands of faintly calcified amorphous or crystalline material, apparently lying haphazardly throughout the tumour, but being found more often in areas where the more mature cell predominates.

'In a few areas only the tissue is composed almost entirely of masses of darkly staining small round cells, sometimes showing a peritheliomatous arrangement or forming the characteristic rosette of a neuroblastoma (Fig. 8). Frequently they are found, in small groups, intimately mixed with the intermediate cell or with the chrome-positive variety.

'Although the intermediate cell might be considered to be a phaeochromoblast, or precursor of the phaeochromocyte, the failure to demonstrate any chromepositive material in such sheets of cells, perhaps coupled with the small total quantity of noradrenaline extracted from a tumour which consists mainly of such cells, is against such hypothesis. Further, the development of such intermediate cells into mature ganglion cells can be seen from a study of several areas of the tumour, whereas no mature phaeochromocytes can be identified.'

Assay of Catecholoamines in the Tumour. Acid extraction of the tumour and alumina absorption of catecholoamines showed a concentration of $235 \mu \mathrm{g} . / \mathrm{g}$. of tumour by biological assay.

Subsequent Progress. Fifteen months after operation, the child was well. There was no sweating, blood pressure was $100 / 50 \mathrm{~mm}$. $\mathrm{Hg}$ and the Hingerty test was negative. There was no evidence of secondary deposits from the tumour.

\section{Discussion}

In attributing functional activity to this neuroblastoma a number of factual points must be considered. Unless a tumour such as this is examined by serial section in its entirety its total cell content remains questionable. Gradations between the normally functionless neuroblastoma and the fully differentiated ganglioneuroma are, of course, not unusual, and are reported by various authors as ganglioneuroblastomas; this would, perhaps, be a more accurate designation of the tumour we describe. Reference may be made to Russell and Rubinstein (1959) for current opinion on differentiation and functional activity in nerve tissue tumours. These authors stated that progress by cellular differentiation to a phaeochromocytoma in 
the neuroblastomas was rare, but had been recognized since Wahl's (1914) report; they also mentioned the paper by Fernando, Cooray and Thanabalasundram (1951) describing neuroblastic elements in a functionally active phaeochromocytoma. In addition they stated that in the case of Mason et al. (1957) the portion of the tumour used to confirm the presence of pressor amines might possibly have been the portion containing phaeochromocytes. Describing three patients with noradrenaline secreting neuroblastomas, Isaacs, Medalie and Politzer (1959) concluded that neuroblasts themselves were responsible for the secretion of catecholamines or for the hyperstimulation of normal chromaffin tissue, and that if the former was acceptable it implied that chromaffin tissue was not essential for the production of catecholamines. The potential complexity of the cell content of any tumour originating from the primitive neural crest must inevitably make classification difficult, although it is easy to understand how more than one element can be represented. The tumour reported here is of interest clinically inasmuch as, although it behaves as a phaeochromocytoma, it is essentially a malignant ganglioneuroblastoma. Only to this extent can this report add information on the origin of the catecholamine secretion. Endless speculation is possible on the findings in this patient, and we shall discuss only two points. First, reasons for the fact that catecholamine secretion in neuroblastomas has only recently been recognized and second the bearing of functional activity on the prognosis.

A likely reason for Mason's et al. (1957) case being the first reported is that the biological assay of catecholamines is itself a recent introduction and that previously no method was available to detect functional activity had this been suspected. However, it does seem odd that in the 44 personal cases of neuroblastoma described by Koop, Kiesewetter and Horn (1955), the 80 cases reviewed by Ware (1956) and the 22 personal cases of intrathoracic neuroblastoma and ganglioneuroblastoma

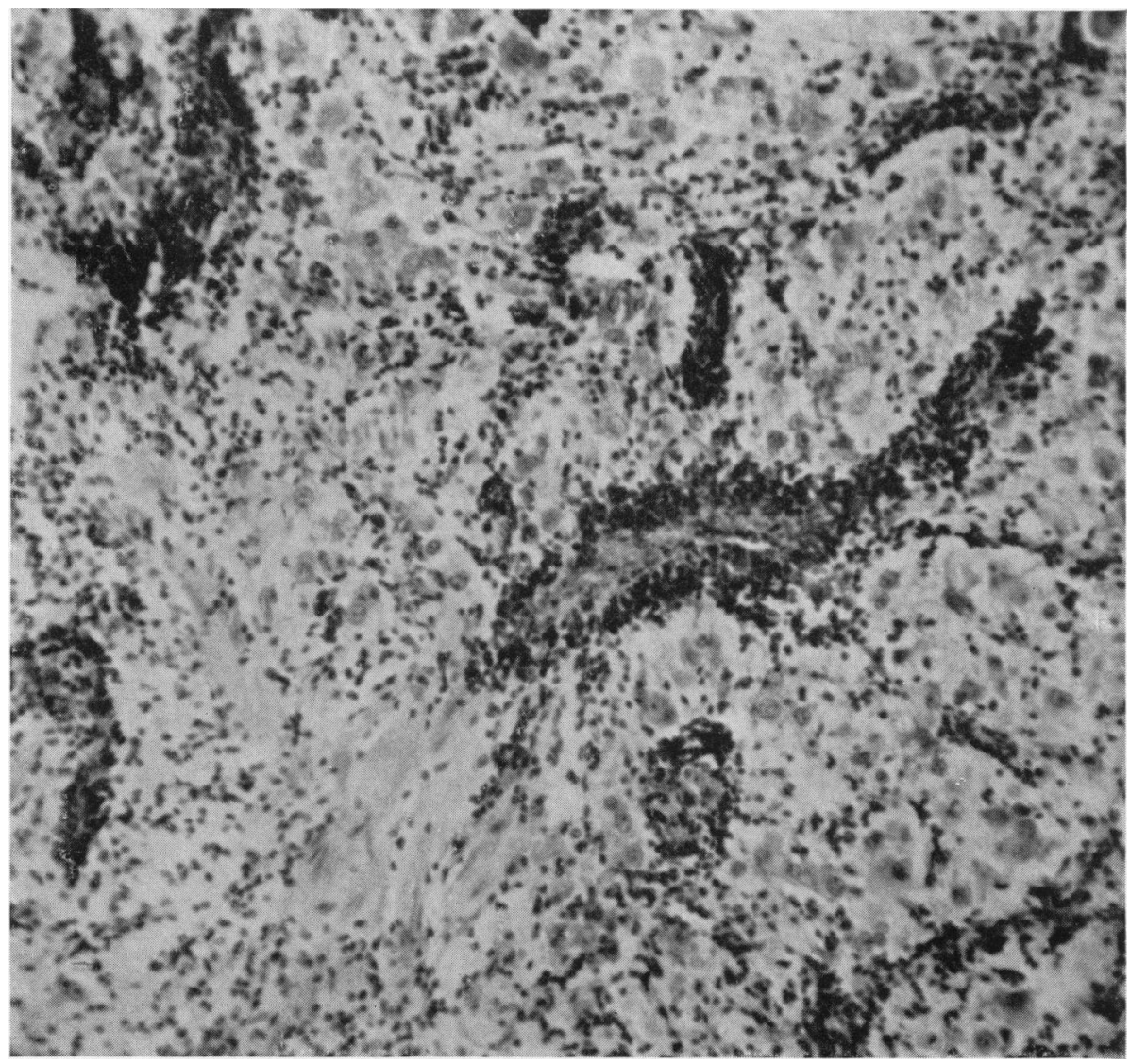

FiG. 8.-( $\times$ 76. $)$ 
reported by Schweisguth, Mathey, Renault and Binet (1959), neither elevation of the blood pressure nor excessive sweating is recorded in a single instance. If the condition is so uncommon it seems difficult to explain the reporting of a number of cases, including the present one, since 1957.

It seems safe to assume that functional activity has existed without being recognized, notably in the patient described by Alexander (1951) in which a brilliant result was obtained from operative removal of the neuroblastoma. The patient, a 3-month-old boy, was admitted to hospital in 1948. Profuse sweating was the only symptom. A radiograph of the chest revealed a shadow in the left lower zone. The tumour, reported as a highly cellular malignant growth arising from the sympathetic nervous system, was removed shortly after the infant's admission to hospital. He was free of symptoms on discharge from hospital one month after operation. James Thomson of Dundee, who originally referred the patient for surgery, has let us know the child's present condition (Thomson, 1960). The boy is now aged 11, has no recurrence of the tumour nor of the excessive sweating, and the blood pressure is $125 / 70 \mathrm{~mm}$. $\mathrm{Hg}$. The history, type of tumour and abrupt cessation of sweating after operation suggest the tumour was functionally active at the time of operation. An interesting, and possibly confirmatory, feature is that the tumour was in the same position in the thorax, namely the left lower zone, as in the case described by Mason et al. (1957) and our own. These three chest films, in fact, bear a striking resemblance to each other. In contrast, in the 22 cases reported by Schweisguth et al. (1959), in which no functional activity was present, none of the tumours they described was situated in this position in the thorax. Reverting to reasons for the recent recognition of functional activity in neuroblastomas, it is possible that this activity may be temporary and occurs only during a phase of the tumour's maturation. Thus it would be possible to explain the failure in the past to record excessive sweating over a number of years as a symptom. In modern practice sweating would be regarded as an indication for estimation of catecholamine levels in the blood and urine and functional activity would be confirmed by this method. Persistent pyrexia was recorded by Ware (1956) in 13 of the 80 cases recorded and in some of these activity may have existed, though sweating was not specifically described. It is difficult to imagine such gross symptoms arising from the presence of the tumour, as in our case, continuing till death and not being remarked upon if this functional activity once established does, in fact, continue to the time of the patient's death. On the grounds of the neuroblastoma's known tendency to revert toward the fully differentiated and, as far as is known, functionless ganglioneuroma, we postulate this reversion occurring spontaneously in the type of neuroblastoma under discussion, as part of the natural history of the tumour and that conceivably some of these tumours become symptomless ganglioneuromas of adult life. (This hypothesis is strengthened by the fact that although the prognosis appears unfavourable, the active neuroblastomas surgically removed have progressed well after operation.) Koop et al. (1955) considered the prognosis was good if the patient survived 14 months after excision of a neuroblastoma.

No patient living this period after operation subsequently died. Each of the intrathoracic adrenaline secreting neuroblastomas recorded (Alexander, 1951; Mason et al., 1957; and the present case) have all survived this period in normal health. We take this to indicate that the tumour may be undergoing spontaneous reversion to the fully differentiated benign state during the period before operation, and had these children been observed over a longer period, functional activity might have ceased spontaneously. We mention this as a hypothetical possibility to explain certain features and not as a method of treating the disease. An explanation such as this may be a tortuous way of stating that a predominantly malignant tumour is more likely to exhibit functional activity than one predominately benign and fully differentiated, namely the ganglioneuroma. Greenberg and Gardner (1959) have reported a patient from whom a ganglioneuroma was removed. Before operation $148 \mu \mathrm{g}$. of neoepinephrine and $3.6 \mu \mathrm{g}$. epinephrine were present in the urine in a 24-hour period. After removal of the tumour the values fell to $17 \cdot 1$ $\mu \mathrm{g}$. and $0.65 \mu \mathrm{g}$. respectively. (Such evidence complicates the hypothesis we put forward, but it could be argued that the urinary values of catecholamines were relatively low because the tumour was benign.) Until more facts become available, reasons for failing to recognize excessive sweating and raised blood pressure in certain non-chromaffin nerve tissue tumours before the description by Mason et al. (1957), must remain in doubt. There are so few cases of this disease reported that a late prognosis based on these reports must be unconvincing. In addition to the remote prognosis, operative removal of the tumour is likely to be more hazardous if the urine is found to contain raised levels of free pressor amines. Mason et al. (1957) described the methods they used to influence sudden 
fluctuations of blood pressure during and immediately following operation. A similar routine was used in our case, except that our patient was not digitalized before operation. We can find no reference to unexplained death during operation on children with neuroblastoma and it is possible therefore, excretion of pressor amines notwithstanding, that the risks of operation are not materially increased. By contrast, removal of a phaeochromocytoma, accompanied usually by very much higher blood levels of pressor amines, is a grave undertaking. This difference can be explained by the different pressor amine content of the two types of tumour. The Hingerty (1957) test is a most useful test for the screening of these infants; it is speedy and sensitive. Sandler and Ruthven (1959) have shown that the urinary excretion of vanylmandelic acid (V.M.A.) is raised in patients with adrenaline secreting tumours and that the urinary V.M.A. determinations represent a more reliable method for ascertaining the presence of an adrenaline secreting tumour.

\section{Summary}

The clinical findings in a child with an intrathoracic neuroblastoma associated with excessive secretion of catecholamines are described. Reasons for the activity in such tumours being only recently recognized and the prognosis are briefly discussed.
Details of the pathology of the tumour are presented.

We should like to thank Mr. B. A. Callingham of the London School of Pharmacy, Dr. D. R. Rigg who anaesthetized the child, and Dr. D. F. Barrowcliff for details of the pathology of the tumour. Mr. T. Skuse and Mr. L. Hine of the Central Pathological Laboratory, Warwick, prepared and photographed the specimen.

\section{REFERENCES}

Alexander, R. C. (1951), Mediastinal neuroblastoma in an infant. Brit. J. Surg., 38, 517.

Fernando, P. B., Cooray, G. H. and Thanabalasundram, R. S. (1951). Adrenal pheochromocytoma with neuroblastomatous elements Report of a case with autopsy. A.M.A.Arch. Path., 52, 182.

Greenberg, R. E. and Gardner, L. I. (1959). New diagnostic test for neural tumors of infancy. Increased urinary excretion of 3-methoxy-4-hydroxymandelic acid and norepinephrine in ganglioneuroma with chronic diarrhea. Pediatrics, 24, 683.

Hingerty, D. (1957). Thirty-minute screening test for phaeochromocytoma. Lancet, 1, 766.

Isaacs, H., Medalie, M. and Politzer, W. M. (1959). Noradrenalinesecreting neuroblastoma. Brit. med. J., 1, 401

Koop, C. E., Kiesewetter, W. B. and Horn, R. C. (1955). Neuroblastoma in childhood. Surgery, 38, 272.

Mason, G. A., Hart-Mercer, J., Millar, E. J., Strang, L. B. and Wynne, N. A. (1957). Adrenaline-secreting neuroblastoma in an infant. Lancet, $2,322$.

Russell, Dorothy S. and Rubinstein, L. J. (1959). Pathology of Tumours of the Nervous System. Arnold, London.

Sandler, M. and Ruthven, C. R. J. (1959). Quantitative colorimetric method for estimation of 3-methoxy-4-hydroxymandelic acid in urine. Value in diagnosis of phaeochromocytoma. Lancet, 2, 114 .

Schweisguth, O. Mathey, J., Renault, P. and Binet, J. P. (1959) Intrathoracic neurogenic tumors in infants and children: a study of forty cases. Ann. Surg., 150, 29

of forty cases. Ann. Surg., 150, 29.
Thomson, J. (1960). Personal communication.

Wahl, H. R. (1914). Neuroblastomata: with a study of a case illustrating the three types that arise from the sympathetic system. J. med. Res., 30, 205.

Ware, G. W. (1956). Thoracic neuroblastoma. J. Pediat., 49, 765. 